\title{
Evolving concepts of sensory adaptation
}

\author{
Michael A. Webster
}

Address: Department of Psychology, University of Nevada, Reno, Reno NV 89557, USA

Email: mwebster@unr.edu

FI000 Biology Reports 2012, 4:2I (doi:10.34I0/B4-2I)

This is an open-access article distributed under the terms of the Creative Commons Attribution-Non Commercial License (http://creativecommons.org/licenses/by-nc/3.0/legalcode), which permits unrestricted use, distribution, and reproduction in any medium, provided the original work is properly cited. You may not use this work for commercial purposes.

The electronic version of this article is the complete one and can be found at: http://fl000.com/reports/b/4/2 I

\begin{abstract}
Sensory systems constantly adapt their responses to match the current environment. These adjustments occur at many levels of the system and increasingly appear to calibrate even for highly abstract perceptual representations of the stimulus. The similar effects of adaptation across very different stimulus domains point to common design principles but also continue to raise questions about the purpose of adaptation.
\end{abstract}

\section{Introduction}

The sensory systems we use to monitor the world around us are not static and instead are continuously recalibrating to adjust for changes in the environment (e.g. in the lighting or temperature) or to compensate for changes in the observer (e.g. with aging or disease). For example, the aromas that lure you into a room (or warn you away!) fade quickly from awareness once you enter, while your perception of color can change dramatically depending on the colors seen previously (Figure 1). These rapid sensitivity adjustments are known as adaptation (changes in the response properties of neurons induced by the recent stimulus context) and suggest that much of our perceptual experience is relative to the stimuli we have experienced recently. Studies of adaptation have a very rich history in perceptual science, because the perceptual "aftereffects" of the adaptation can provide clues as to how our senses encode and represent the stimulus $[1,2]$. A wide variety of aftereffects have been documented, including classic perceptual illusions, such as a bias in what looks vertical after viewing tilted lines [3], or a change in what looks stationary after adapting to movement [4]. However, these studies have traditionally focused on simple perceptual properties and, thus, potentially early stages of neural coding. Recently, the study of adaptation has been extended to much more complex and naturalistic attributes, and this has revealed both new insights and new questions about sensory coding and the role of adaptation. While this review focuses on vision, the findings and principles that have emerged are likely to be general to all of the senses as well as their interactions.

\section{Stages of adaptation}

In the visual system, multiple stages of adaptation are welldocumented. Adjusting to changes in average brightness or color begins as early in visual coding as the photoreceptors [5], while adjusting to different patterns of light (e.g. to the orientation of edges or the direction of motion) reflects changes at more central levels [6]. In humans, these pattern-selective aftereffects are thought to include response changes in the cortex, in part because cells with the receptive fields that can distinguish orientation or movement direction first appear in the cortex [7], and also because adaptation in one eye often affects the appearance of patterns seen through the other [8] (and inputs from the two eyes first converge in primary visual cortex). But vision is mediated by myriad cortical levels and areas [9], raising the question of whether the processes of adaptation are manifested throughout the visual stream. One suggestion for this is the growing demonstration of "high-level" pattern aftereffects, which have shown that adaptation can influence the perception of complex and much more abstract properties of the stimulus [1,10]. For example, the identity [11] or characteristics of a person, such as their gender [12] can be biased by prior exposure to a male or female face or to feminine or masculine traits (e.g. walking style [13,14]) (Figure 2). 
Figure I. Color afterimages

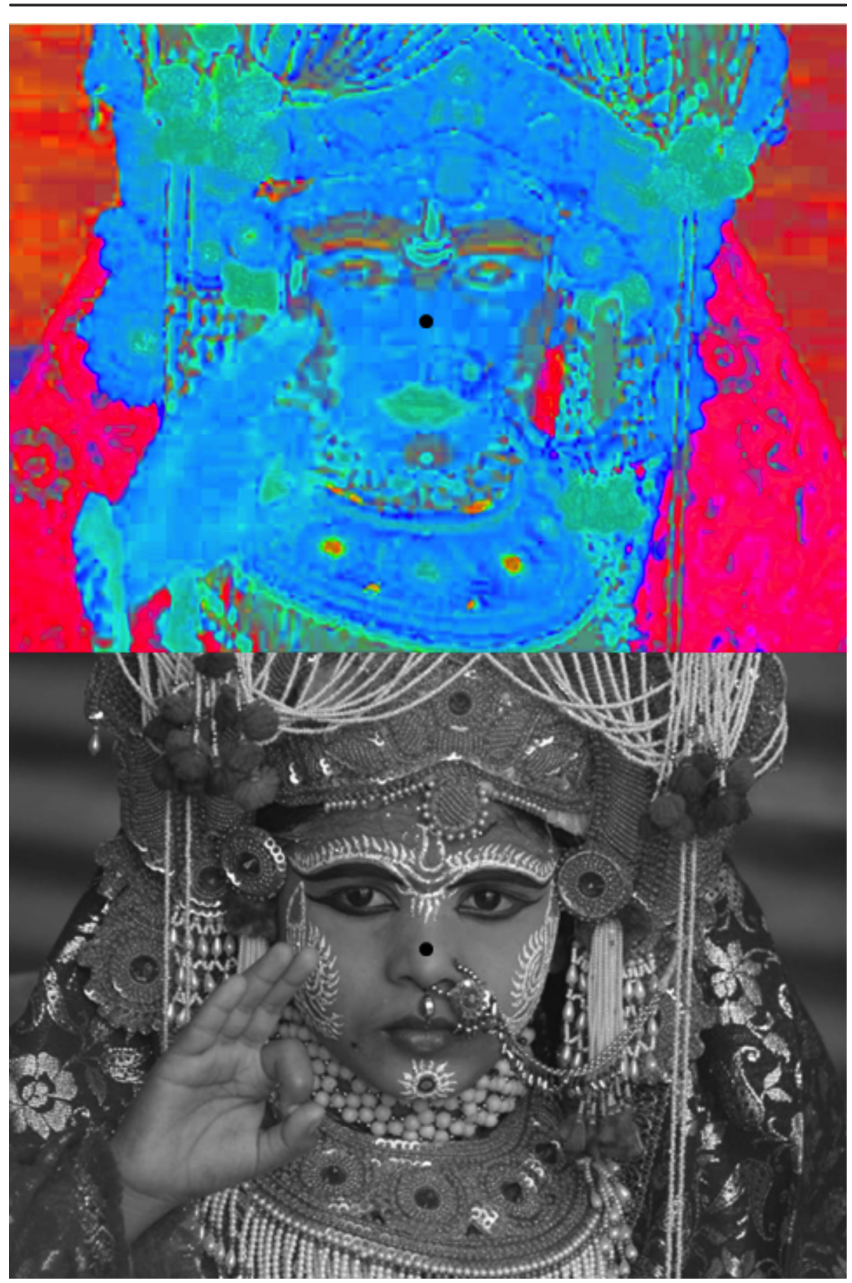

An example of a perceptual aftereffect, similar to the "Big Spanish Castle" illusion popularized on the internet [88]. The upper image is a pseudonegative of the original photograph (with color differences exaggerated and brightness differences reduced). Stare at the black dot in the upper image for 30 seconds or more and then quickly switch your gaze to the dot in the lower picture. The grayscale image should briefly appear colored. The illusory colors are opposite to the adapting colors, a "negative aftereffect" typical in adaptation. This occurs because adaptation reduces sensitivity to the local adapting color and, thus, biases perception toward the complementary color. Note also that the aftereffect is visible only when the afterimage is in register with the grayscale image (by fixating the dots). This occurs because the colors in the afterimage tend to fill-in between the luminance boundaries and, thus, blend together in different ways depending on the position of the borders [87]. This illustrates that adaptation effects that arise very early in the visual system can be modulated at more central levels [22].

Adaptation also affects the perception of more abstract attributes of objects (e.g. their three-dimensional viewpoint [15]), scenes (e.g. how panoramic they appear [16]), and materials (e.g. whether a surface looks glossy or matte [17]). Further, even seemingly simpler pattern aftereffects, such as the tilt or movement of an edge can depend on higher-level attributes [18], such as whether the test and adapt edges appear to belong to the same object [19]. The similar consequences of adaptation on both simple and complex perceptual judgments may, thus, indicate that adaptation operates at all levels of visual coding. In turn, this suggests that the visual system may draw on fundamentally similar strategies to represent very different forms of information, and that adaptation serves a common function within these representations $[20,21]$. However, these findings have also challenged basic notions about adaptation.

An important issue is whether high-level aftereffects necessarily reflect response changes at the high-processing levels at which the adapted attribute is explicitly represented. For example, do face aftereffects depend on adaptation in neurons that directly encode the stimulus as a face? Identifying the sites of adaptation is difficult because sensitivity changes that arise early in the visual system will propagate to later stages, and, thus, complex aftereffects could reflect changes inherited from earlier levels $[22,23]$. This has been illustrated in face adaptation by showing that aftereffects of perceived expression can be induced by exposure to curved [24] or oriented [25] lines, which are not themselves face-like. Moreover, there is increasing evidence that neurons very early in the visual system, in the retinal layers of the eye, can also exhibit a surprising range of plasticity [26]. This can include selective adjustments to patterns like motion and orientation that the cells are not directly tuned for, so that even at this early stage it becomes difficult to disentangle the adaptive behaviour of individual neurons from the processing network $[27,28]$. Consequently, there is no question that complex images engage adaptation at early levels of visual coding. However, a number of approaches have been used to try to isolate additional, more-central sites of sensitivity change [20]. These include varying the size [29], position [30], or orientation [31] of the adapt and test stimuli so that they are less likely to be "seen" by the same lower-level mechanisms. They also include testing whether the adaptation transfers between adapt and test stimuli that are more similar conceptually than perceptually. For example, gender aftereffects can be induced in images of faces after adapting to male or female headless bodies [32], and motion aftereffects can occur in stimuli after adapting to static images [33] or even passages of text [34] that convey movement. Gender aftereffects also depend on the perceptual category of the stimuli rather than simply their physical similarity $[35,36]$. Finally, distinct high-level aftereffects have also been implicated by showing that the adaptation has different properties than low-level aftereffects, such as the time course [18] or susceptibility to awareness [37], or that it alters percepts in qualitatively different ways [38]. Overall, 
Figure 2. Face aftereffects

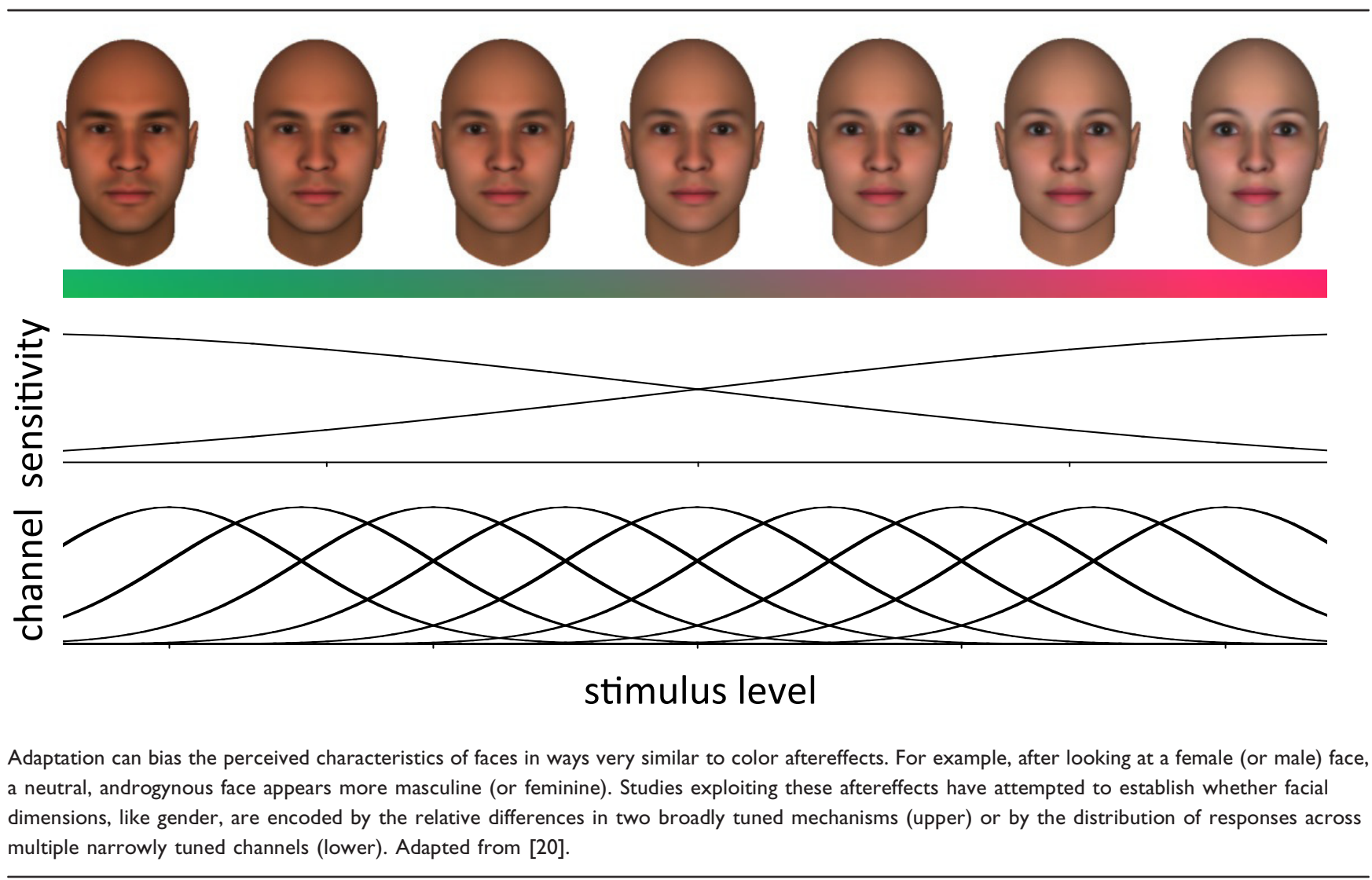

such findings suggest that adaptation probably is intrinsic to all levels of sensory coding and ranks among a basic set of "canonical" computations used throughout the brain to govern activity [39]. Because of this, caution is needed in identifying an aftereffect with specific levels of processing.

\section{Selectivity of visual aftereffects}

If adaptation is happening throughout the visual stream, can we use aftereffects to decipher the coding of high-level attributes in the same way that adaptation has revealed how information is sampled by early visual mechanisms? A frequent goal of adaptation studies has been to characterize the number and selectivity of adaptable mechanisms representing a stimulus dimension [6]. The assumption is that if adaptation to one stimulus alters sensitivity to another, then both are detected by a common filter or channel, and, thus, the spread of the aftereffects can be used to measure how many different channels might span the dimension and their bandwidths. This approach has been actively extended to high-level perceptual attributes in the study of how the visual system is organized to represent faces [20]. Two standard models of face coding are an exemplar-based code - where each specific identity is represented by a specific neural template or something like the central tendency of the responses across a range of detectors, and a norm-based code - where identity is instead represented in a relative fashion by coding how the individual deviates from an average or prototype face [40] (Figure 2). The exemplar model is reminiscent of orientation or size (spatial frequency) coding, where we might represent the tilt of an edge by the pattern of activity across many channels tuned to different orientations and spatial scales [41]. Norm-based codes are instead similar to color vision, where the dimensions of hue and saturation correspond to how, and how much, the stimulus differs from a neutral gray [42]. In principle, these schemes can be distinguished by the pattern of aftereffects [43]. In a norm-based code, adaptation should readjust the norm (similar to the way that odors or colors fade with exposure), and thus distinctive faces should appear more average the longer we look at them. While there are a number of signs of this normalization [11,44-46], recent studies have questioned whether some facial attributes like gender adapt in ways predicted by simple normalization $[47,48]$. Moreover, interpreting the pattern of aftereffects is, in general, complicated because the selectivity of the adaptation does 
not necessarily predict the selectivity of the underlying detectors $[49,50]$, and the channels may not adapt independently [51]. A further problem is whether the stimulus itself should be treated as narrow (e.g. a single wavelength) or broad (e.g. natural light sources), for adaptation will tend to normalize the appearance of stimuli with broad spectra, even if the underlying channels are highly selective [52].

\section{Functions of adaptation}

Perhaps a deeper question about high-level adaptation is whether it serves the same purpose for visual coding as the sensitivity changes arising at more peripheral stages of the visual system. This is again hard to answer because the functions of adaptation remain surprisingly mysterious $[1,2,53]$. New ideas about its potential utility continue to emerge [54], and it may, in fact, serve a variety of distinct roles, from enhancing discrimination $[55,56]$ to highlighting novelty $[57,58]$ to maintaining perceptual constancy (i.e. invariant percepts despite varying viewing contexts) [59]. At peripheral stages, most theoretical accounts of adaptation have emphasized efficient coding, or how to get the most information out of neurons with very limited dynamic ranges [51,60-63]. The visual system must operate over a daunting range of light levels and adaptation is clearly critical to ensure that neurons are not under- or over-exposed [64]. Information and metabolic efficiency can also be maximized by using a predictive code [65], so that neural resources are not wasted on the expected properties of the stimulus and can instead be devoted to signaling only the unexpected. Normalizing the code through adaptation effectively achieves this by neutralizing and, thus, factoring out responses to the current average stimulus. Such principles have proven to be remarkably powerful in predicting the operating characteristics of early sensory neurons [66]. Yet it remains unclear whether the same constraints continue to dominate at later stages or for higher perceptual attributes, where the range of environmental variation may be much less, and where the goal of sensory coding itself might change. For example, a persistent assumption is that adaptation should help us to distinguish small differences in the patterns we are adapted to, in the same way that adapting to the average light level helps us to distinguishing brightness differences within the scene. Yet demonstrations that we can better distinguish among simple patterns, like gratings [67-69] or complex images like faces [70-72], after we adapt to them are meager in comparison to the striking changes that adaptation induces in their appearance. The linear response functions characterized for some dimensions of facial variation, such as eyeheight, also seem poorly designed to efficiently represent the presumed unimodal distribution of levels in the stimulus $[44,73,74]$. Moreover, adaptation may set the operating state of cortical neurons too low to maximize information transmission, perhaps because these neurons are instead designed to reliably detect novel features [75].

\section{Dynamics of adaptation}

The feedback signals that might allow a neuron to know when it should adapt are also poorly understood. Adaptation is clearly a process of adjusting sensitivity relative to some underlying reference level, but what sets this level? Often pattern aftereffects are assumed to be onesided, so that adaptation reduces, but never enhances, sensitivity. However, this assumes a baseline sensitivity set by no stimulation at all. In reality, we are adapted to the world around us, so that the stimulus could change by becoming stronger or weaker. When observers are adapted to a world with artificially lower contrast, they in fact become more sensitive to contrast $[76,77]$. Recent work suggests that these baseline states are themselves determined by long-term adaptation to the environment, and that there may be distinct adaptation adjustments operating over multiple timescales [78-81]. Moreover, these may be designed to calibrate for different properties of the stimulus distribution, such as the mean versus maximum level [77]. Varying rates of adaptation may be important for optimally tracking different rates of change in the environment or the organism. For example, it makes sense to adapt quickly but recover rapidly when the change is transient (e.g. muscle fatigue), while adjusting more slowly when the change is more persistent (e.g. development or damage) [82-84]. The dynamics of adaptation may also need to vary in order to ensure that adjustments are driven by actual changes in the signal rather than noise [85]. Finally, when observers are repeatedly exposed to a different context, there is evidence that the dynamics also adjust so that they can "learn" to adapt more quickly to the change [86]. These results raise the intriguing possibility that the visual system might store different operating states for different contexts (e.g. whether our glasses are on or off), allowing rapid switches between them. Such findings are not only extending the concept of high-level adaptation to more complex stages of visual analysis but also to more complex forms of sensory calibration.

\section{Summary and future directions}

Studies of adaptation continue to reveal surprising and complex forms of plasticity in sensory systems, from peripheral receptors to central mechanisms coding highly abstract properties of the stimulus. The finding that vision adapts in such similar ways to such a diverse array of perceptual attributes suggests that adaptation is an intrinsic feature of visual coding that is manifest throughout the visual stream. However, we still understand little about the dynamics and mechanisms of these adjustments, how they 
operate over different timescales, and whether they serve common or distinct roles in calibrating our perceptions.

\section{Competing interests}

The author declares that he has no competing interests.

\section{Acknowledgements}

Supported by NIH grant EY-10834.

\section{References}

I. Webster MA: Adaptation and visual coding. J Vis 20I I, I I (3): I-23.

2. Clifford CW, Webster MA, Stanley GB, Stocker AA, Kohn A, Sharpee TO, Schwartz O: Visual adaptation: neural, psychological and computational aspects. Vision Research 2007, 47: 3|25-3|.

3. Gibson JJ, Radner M: Adaptation, after-effect and contrast in the perception of tilted lines. I. Quantitative studies. Journal of Experimental Psychology 1937, 20:453-67.

4. Wohlgemuth A: On the aftereffect of seen movement. British Journal of Psychology Monograph Supplement I91 I, I:I-II7.

5. Stockman A, Langendorfer M, Smithson HE, Sharpe LT: Human cone light adaptation: from behavioral measurements to molecular mechanisms. J Vis 2006, 6:1 194-213.

\section{FlOOOPrime}

\section{RECOMMENDED}

6. Graham NV: Visual Pattern Analyzers. Oxford: Oxford University Press; 1989.

7. Hubel DH, Wiesel TN: Receptive fields and functional architecture of monkey striate cortex. J Physiol 1968, 195:215-43.

8. Blake R, Overton R, Lema-Stern S: Interocular transfer of visual aftereffects. J Exp Psychol Hum Percept Perform 198I, 7:367-8I.

9. Felleman DJ, Van Essen DC: Distributed hierarchical processing in the primate cerebral cortex. Cereb Cortex 199|, I:I-47.

10. Clifford CWG, Rhodes G: Fitting the Mind to the World: Adaptation and Aftereffects in High-Level Vision, Advances in Visual Cognition Series, Volume 2. Oxford: Oxford University Press; 2005.

II. Leopold DA, O'Toole AJ, Vetter T, Blanz V: Prototype-referenced shape encoding revealed by high-level aftereffects. Nature Neuroscience 2001, 4:89-94.

\section{FlOOOPrime}

12. Webster MA, Kaping D, Mizokami Y, Duhamel P: Adaptation to natural facial categories. Nature 2004, 428:557-6I.

13. Jordan H, Fallah M, Stoner GR: Adaptation of gender derived from biological motion. Nature Neuroscience 2006, 9:738-9.

14. Troje NF, Sadr J, Geyer H, Nakayama K: Adaptation aftereffects in the perception of gender from biological motion. Journal of Vision 2006, 6:850-7.

15. Fang $\mathrm{F}, \mathrm{He} \mathrm{S}$ : Viewer-centered object representation in the human visual system revealed by viewpoint aftereffects. Neuron 2005, 45:793-800.

\section{FlOOOPrime}

16. Greene MR, Oliva A: High-level aftereffects to global scene properties. J Exp Psychol Hum Percept Perform 2010, 36:।430-42.

FlOOOPrime RECOMMENDED

17. Motoyoshi I, Nishida S, Sharan L, Adelson EH: Image statistics and the perception of surface qualities. Nature 2007, 447:206-9.

18. Suzuki S: High-level pattern coding revealed by brief shape aftereffects. In Fitting the Mind to the World: Adaptation and Aftereffects in High-Level Vision, Advances in Visual Cognition Series, Volume 2. Edited by Clifford C, Rhodes G. Oxford: Oxford University Press; 2005.
19. von der Heydt R, Macuda T, Qiu FT: Border-ownership-dependent tilt aftereffect. J Opt Soc Am A Opt Image Sci Vis 2005, 22:2222-9.

FlOOOPrime

20. Webster MA, MacLeod DIA: Visual adaptation and face perception. Philos Trans R Soc Lond B Biol Sci 201 I, 366:1702-25.

21. Clifford CWG: Perceptual adaptation: motion parallels orientation. Trends in Cognitive Sciences 2002, 6:136-43.

22. Zaidi Q, Ennis R, Cao D, Lee B: Neural locus of color afterimages. Curr Biol 2012, 22:220-4.

\section{FlOOOPrime} RECOMMENDED

23. Kohn A, Movshon JA: Neuronal adaptation to visual motion in area MT of the macaque. Neuron 2003, 39:68I-9I.

FIOOOPRime

24. Xu H, Dayan P, Lipkin RM, Qian N: Adaptation across the cortical hierarchy: Low-level curve adaptation affects high-level facial-expression judgments. Journal of Neuroscience 2008, 28: 3374-83.

25. Dickinson JE, Almeida RA, Bell J, Badcock DR: Global shape aftereffects have a local substrate: A tilt aftereffect field. J Vis 2010, 10:5

26. Gollisch T, Meister M: Eye smarter than scientists believed: neural computations in circuits of the retina. Neuron 2010, 65:150-64.

\section{FlOOOPrime
RECOMMENDED}

27. Olveczky BP, Baccus SA, Meister M: Retinal adaptation to object motion. Neuron 2007, 56:689-700.

28. Hosoya T, Baccus SA, Meister M: Dynamic predictive coding by the retina. Nature 2005, 436:7I-7.

\section{FIOOOPrime}

29. Chubb C, Sperling G, Solomon JA: Texture interactions determine perceived contrast. Proc Natl Acad Sci U S A 1989, 86:963I-5.

30. Afraz $A, C$ avanagh $P$ : The gender-specific face aftereffect is based in retinotopic not spatiotopic coordinates across several natural image transformations. Journal of Vision 2009, 9(10): II-7.

31. Watson TL, Clifford CWG: Pulling faces: An investigation of the face-distortion aftereffect. Perception 2003, 32:1 109-16.

\section{FIOOOPrime}

32. Ghuman AS, McDaniel JR, Martin A: Face Adaptation without a Face. Current Biology 2010, 20:32-6.

33. Winawer J, Huk AC, Boroditsky L: A motion aftereffect from still photographs depicting motion. Psychol Sci 2008, 19:276-83.

\section{FIOOOPrime}

34. Dils AT, Boroditsky L: Visual motion aftereffect from understanding motion language. Proc Natl Acad Sci U S A 2010, 107:16396-400.

35. Bestelmeyer PEG, Jones BC, DeBruine LM, Little AC, Perrett DI, Schneider A, Welling LLM, Conway CA: Sex-contingent face aftereffects depend on perceptual category rather than structural encoding. Cognition 2008, 107:353-65.

36. Rotshtein P, Henson RN, Treves A, Driver J, Dolan RJ: Morphing Marilyn into Maggie dissociates physical and identity face representations in the brain. Nature Neuroscience 2005, 8:107-I3.

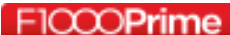

\section{RECOMMENDED}

37. Moradi F, Koch C, Shimojo S: Face adaptation depends on seeing the face. Neuron 2005, 45:169-75. 
38. He D, Kersten D, Fang F: Opposite modulation of high- and lowlevel visual aftereffects by perceptual grouping. Current Biology 2012, 22:1040-5.

39. Carandini M, Heeger DJ: Normalization as a canonical neural computation. Nat Rev Neurosci 20I I, 13:5 I-62.

\section{FlOOOPRime
RECOMMENDED}

40. Valentine T, Endo M: Towards an exemplar model of face processing: the effects of race and distinctiveness. Quarterly Journal of Experimental Psychology A 1992, 44:67I-703.

41. Blakemore C, Campbell FW: On the existence of neurones in the human visual system selectively sensitive to the orientation and size of retinal images. Journal of Physiology 1969, 203:237-60.

42. Webster MA: Human colour perception and its adaptation. Network: Computation in Neural Systems 1996, 7:587-634.

43. Rhodes G, Robbins R, Jaquet E, McKone E, Jeffery L, Clifford CWG: Adaptation and face perception - how aftereffects implicate norm based coding of faces. In Fitting the Mind to the World: Adaptation and Aftereffects in High-Level Vision. Edited by Clifford CWG, Rhodes G. Oxford: Oxford University Press; 2005:2 I 3-40.

44. Robbins R, McKone E, Edwards M: Aftereffects for face attributes with different natural variability: Adapter position effects and neural models. Journal of Experimental Psychology-Human Perception and Performance 2007, 33:570-92.

45. Rhodes G, Jeffery L: Adaptive norm-based coding of facial identity. Vision Research 2006, 46:2977-87.

46. Webster MA, MacLin OH: Figural aftereffects in the perception of faces. Psychonomic Bulletin and Review 1999, 6:647-53.

47. Zhao C, Series P, Hancock PJ, Bednar JA: Similar neural adaptation mechanisms underlying face gender and tilt aftereffects. Vision Res 201I, 5 I:202I-30.

48. Storrs KH, Arnold DK: Not all face aftereffects are equal. Vision Research in press.

49. Hegde J: How reliable is the pattern adaptation technique? A modeling study. J Neurophysiol 2009, 102:2245-52.

\section{FlOOOPrime} RECOMMENDED

50. Mur M, Ruff DA, Bodurka J, Bandettini PA, Kriegeskorte N: Faceidentity change activation outside the face system: "release from adaptation" may not always indicate neuronal selectivity. Cereb Cortex 2010, 20:2027-42.

51. Barlow HB: A theory about the functional role and synaptic mechanism of visual aftereffects. In Visual Coding and Efficiency. Edited by Blakemore C. Cambridge: Cambridge University Press; 1990:363-75.

52. Elliott SL, Georgeson MA, Webster MA: Response normalization and blur adaptation: Data and multi-scale model. J Vis $201 \mathrm{I}, \mathrm{I}$ I.

53. Kohn A: Visual adaptation: physiology, mechanisms, and functional benefits. J Neurophysiol 2007, 97:3155-64.

54. Chopin A, Mamassian P: Predictive properties of visual adaptation. Curr Biol 22:622-6.

55. Ohzawa I, Sclar G, Freeman RD: Contrast gain control in the cat visual cortex. Nature 1982, 298:266-8.

56. Greenlee MW, Heitger F: The functional role of contrast adaptation. Vision Res 1988, 28:79I-7.

57. McDermott KC, Malkoc G, Mulligan JB, Webster MA: Adaptation and visual salience. J Vis 2010, 10:17.

58. Ranganath C, Rainer G: Neural mechanisms for detecting and remembering novel events. Nat Rev Neurosci 2003, 4:193-202.

59. Foster DH: Color constancy. Vision Res 2011, 51:674-700.

60. Wark B, Lundstrom BN, Fairhall A: Sensory adaptation. Curr Opin Neurobiol 2007, 17:423-9.

61. Wainwright MJ: Visual adaptation as optimal information transmission. Vision Res 1999, 39:3960-74.
62. Sharpee TO, Sugihara H, Kurgansky AV, Rebrik SP, Stryker MP, Miller KD: Adaptive filtering enhances information transmission in visual cortex. Nature 2006, 439:936-42.

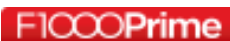

RECOMMENDED

63. Laughlin S: A simple coding procedure enhances a neuron's information capacity. Z Naturforsch C 1981, 36:910-2.

\section{FIOOOPrime}

RECOMMENDED

64. Rieke F, Rudd ME: The challenges natural images pose for visual adaptation. Neuron 2009, 64:605-16.

65. Srinivasan MV, Laughlin SB, Dubs A: Predictive coding: a fresh view of inhibition in the retina. Proc $R$ Soc Lond B Biol Sci 1982, 216:427-59.

\section{FlOOOPrime}

\section{RECOMMENDED}

66. Simoncelli EP, Olshausen BA: Natural image statistics and neural representation. Annu Rev Neurosci 200I, 24:1 193-216.

67. Barlow HB, Macleod DI, van Meeteren A: Adaptation to gratings: no compensatory advantages found. Vision Research 1976, 16:1043-5.

68. Clifford CWG, Wyatt AM, Arnold DH, Smith ST, Wenderoth P: Orthogonal adaptation improves orientation discrimination. Vision Research 200I, 41: I5I-9.

69. Westheimer G, Gee A: Orthogonal adaptation and orientation discrimination. Vision Research 2002, 42:2339-43.

70. Rhodes G, Watson TL, Jeffery L, Clifford CW: Perceptual adaptation helps us identify faces. Vision Research 2010, 50:963-8.

7I. Ng M, Boynton GM, Fine I: Face adaptation does not improve performance on search or discrimination tasks. Journal of Vision 2008, 8(I): I-20.

72. Armann R, Jeffery L, Calder AJ, Rhodes G: Race-specific norms for coding face identity and a functional role for norms. J Vis $201 \mathrm{I}, \mathrm{I} I$ : 9.

73. Susilo $T$, McKone E, Edwards M: What shape are the neural response functions underlying opponent coding in face space? A psychophysical investigation. Vision Research 2010, 50:300-I4.

74. Dennett H, Susilo T, McKone E: Face aftereffects predict individual differences in face recognition ability. Psychological Science in press.

75. Ringach DL, Malone BJ: The operating point of the cortex: neurons as large deviation detectors. J Neurosci 2007, 27: 7673-83.

FlOOOPrime RECOMMENDED

76. Zhang P, Bao M, Kwon M, He S, Engel SA: Effects of orientationspecific visual deprivation induced with altered reality. Curr Biol 2009, 19:1956-60.

FlOOOPrime RECOMMENDED

77. Kwon M, Legge GE, Fang F, Cheong AM, He S: Adaptive changes in visual cortex following prolonged contrast reduction. $J$ Vis 2009, 9(20): $1-16$

\section{FlOOOPrime
RECOMMENDED}

78. Neitz J, Carroll J, Yamauchi Y, Neitz M, Williams DR: Color perception is mediated by a plastic neural mechanism that is adjustable in adults. Neuron 2002, 35:783-92.

79. Belmore SC, Shevell SK: Very-long-term and short-term chromatic adaptation: are their influences cumulative? Vision Res 2010, $51: 362-6$.

80. Vul E, Krizay E, MacLeod DI: The McCollough effect reflects permanent and transient adaptation in early visual cortex. Journal of Vision 2008, 8(4): I- 12.

8I. Bao M, Engel SA: Distinct mechanism for long-term contrast adaptation. Proc Natl Acad Sci U S A 2012, 109:5898-903. 
82. Kording KP, Tenenbaum JB, Shadmehr R: The dynamics of memory as a consequence of optimal adaptation to a changing body. Nat Neurosci 2007, 10:779-86.

\section{FlOOOPrime}

\section{RECOMMENDED}

83. Smith MA, Ghazizadeh A, Shadmehr R: Interacting adaptive processes with different timescales underlie short-term motor learning. PLoS Biol 2006, 4:el79.

\section{FlOOOPrime}

\section{RECOMMENDED}

84. Shadmehr R, Smith MA, Krakauer JW: Error correction, sensory prediction, and adaptation in motor control. Annu Rev Neurosci 2010, 33:89-108.
85. Wark B, Fairhall A, Rieke F: Timescales of inference in visual adaptation. Neuron 2009, 61:750-61.

FlOOOPrime

86. Yehezkel O, Sagi D, Sterkin A, Belkin M, Polat U: Learning to adapt: Dynamics of readaptation to geometrical distortions. Vision Res 2010, 50:1550-8.

FlOOOPrime

RECOMMENDED

87. van Lier $R$, Vergeer $M$, Anstis S: Filling-in afterimage colors between the lines. Curr Biol 2009, 19:R323-4.

88. [http://www.johnsadowski.com/big_spanish_castle.php] 